\title{
Relevance of brain imaging studies for social psychiatry
}

\author{
THOMAS BECKER e ULRICH MÜLLER
}

Computerised tomography (CT) and magnetic resonance imaging (MRI) have dramatically changed diagnostic work-up in neurology. Clinical psychiatry has profited from the potential of both diagnostic tools in ruling out focal intracranial pathology (Becker et al., 1995). Also, a multitude of research studies covering the whole range of psychiatric disorders using CT, MRI, magnetic resonance spectroscopy (MRS), positron emission tomography (PET) and single photon emission computed tomography (SPECT) have been published in recent years. MRI, in comparison with CT, has enhanced diagnostic accuracy, particularly in the middle and posterior cranial fossa. Its advantages include an increase in diagnostic sensitivity, free choice of imaging plane, better differentiation of grey and white matter as well as basal ganglia morphology. However, specificity of findings is limited, e.g. where white matter hyperintense lesions are concerned (Becker et al., 1995). SPECT and PET permit the study of cerebral blood flow, regional brain metabolism and neurotransmitter receptor or transporter densities. Both methods require the administration of radioactive tracers, and functional images are produced on the basis of photon or positron emission. PET imaging requires on-site availability of a cyclotron unit to produce adequate tracer substances (with short half-lives) which makes the method inherently expensive.

Brain MRS in psychiatry is still in its infancy, and most studies have been performed using ${ }^{1} \mathrm{H}$ and ${ }^{31} \mathrm{P}$, while some have used ${ }^{7} \mathrm{Li}$ and ${ }^{19} \mathrm{~F}$. The first generation of MRS studies, in schizophrenia, have illuminated some pathophysiological aspects. Noteworthy findings include reduction in $\mathrm{N}$-acetyl aspartate (a

Indirizzo per la corrispondenza: Dr Thomas Becker, Department of Psychiatry, University of Leipzig, Liebigstrasse 22, D04104 Leipzig (Germany).

Fax $+49(0) 341-960.4662$.

E-mail: beckt@medizin.uni-leipzig.de marker for neural integrity) in the temporal lobe and evidence of membrane alterations in prefrontal and temporal cortices. In the affective disorders, ${ }^{31} \mathrm{P}$ MRS demonstrated alterations in the phosphomonoester resonance in bipolar disorder as well as alterations in the high-energy phosphates in bipolar and unipolar depression. ${ }^{19} \mathrm{~F}$ and ${ }^{7} \mathrm{Li}$ MRS, in affective and non-affective psychotic disorders, have also been used to determine brain drug concentrations (e.g., trifluoperazine, fluphenazine, fluoxetine, and lithium) (Keshavan \& Pettegrew, 1997).

Functional MRI (fMRI) will increasingly become the key functional imaging tool (Kindermann et al., 1997). It is based on the functional link between neural activity and brain perfusion; activation of neurons leads to an increase in regional cerebral oxygen demand. Regional perfusion is enhanced to meet this demand which leads to a net increase in local oxygen concentration, particularly in draining veins. This leads to a shift of balance in the ratio between oxyhemoglobin and deoxyhemoglobin favouring the latter - a paramagnetic substance. This blood oxygenlevel dependent (BOLD) contrast can be visualised due to a reduction in magnetic susceptibility which results in signal increase. Experimental stimulation paradigms are used to test functional neural activation. Resting state and active state (and/or different active states) are compared, and sophisticated statistical methods help in assessing activation differences. Study designs which are used in functional brain imaging research include: (a) categorical approaches in which patients and control subjects are compared, (b) parametric experimental designs which are based on the evocation of physiological responses by the systematic variation of an independent (cognitive or behavioural) variable, or (c) factorial experiments which examine interactions between variables in different domains of either cognition, behaviour or external manipulation, for instance by pharmacological agents. These designs can also be combined in clinical studies (Dolan \& Friston, 1997). 


\section{STRUCTURAL IMAGING FINDINGS}

Increased ventricular size is one of the best replicated findings in schizophrenia research, and there is additional evidence of increased external cerebrospinal fluid (CSF) spaces in patient groups. However, a variety of studies have shown these findings not to be specific to schizophrenic disorders, and widening of internal and external CSF spaces has been described also in bipolar affective and schizoaffective disorders. Brain regions in which structural deficit has been reported in patients with schizophrenia include the frontal lobe, temporal lobe and cerebellum (Chua \& McKenna, 1995). Such brain structural abnormalities may be acquired early in life and constitute an unspecific vulnerability marker. Some studies have shown progressive brain structural change in a subgroup of patients which might reflect an active brain disease process (DeLisi et al., 1997, Nair et al., 1997).

\section{CLINICAL CORRELATES OF STRUCTURAL BRAIN ABNORMALITIES}

Poor premorbid adjustment may predict reduced cerebral volume and/or increased sulcal volume in patients with schizophrenia (Harvey et al., 1993). A number of studies have looked at clinical correlates of brain structural abnormalities, particularly in schizophrenia. Some described associations of frontal atrophy or ventricular enlargement and a poor response to neuroleptic treatment or overall poor clinical outcome (Andreasen et al.. 1982). Van Os et al. (1995) found an association of structural deficit on CT/MRI with poor cognitive function and unemployment. Also, a negative association was reported between the extent of white matter hyperintense lesions on MRI and treatment response in depressed patients (Hickie et al., 1995). Figiel et al. (1991), in a further MRI study, reported the risk of neuroleptic-induced parkinsonism to be increased in patients with striatal white matter hyperintense lesions.

\section{REGIONAL BRAIN DYSFUNCTION-SPECT, PET AND FMRI}

In regional cerebral blood flow (rCBF) and PET studies reduced frontal blood flow and a decrease in frontal glucose metabolism have been described in patients with schizophrenia. However, studies have not been unanimous with respect to 'hypofronta- lity' or altered anterior-posterior gradients. With regard to laterality, most studies have found either no hemispheric asymmetries or increased metabolism or blood flow in the left hemisphere, particularly in temporal areas (Swanson et al., 1997). Alterations in striatal D2 receptor density in brains of people suffering from schizophrenia have not been firmly established so far (Okubo et al., 1997). However, recent work has used functional approaches and resulted in findings of striatal D2 receptors being associated with negative symptoms in schizophrenia (Martinot et al., 1994), and also in associations of prefrontal D1 receptors and cognitive deficits (Okubo et al., 1997). Other studies found associations of dysfunctional thalamic-prefrontal circuitry and cognitive deficits (Andreasen et al., 1996, Buchsbaum et al., 1996).

Two recent studies using SPECT and PET demonstrate the degree of spatial resolution and syndrome differentiation which can be attained using these functional imaging methods. Ebmeier et al. (1997) found global depression severity and an independent 'vital depression' factor to be associated with increased perfusion in cingulate and other paralimbic areas, while an 'anxious depression' factor appeared to be associated with reduced frontal neocortical perfusion. In a study combining PET and MRI, Drevets et al. (1997) found an area of abnormally decreased blood flow (in resting state) in the subgenual prefrontal cortex in both familial bipolar and unipolar depressed patients. This decrease in perfusion, however, was at least partly explained by a corresponding reduction in cortical volume, as MRI demonstrated reductions in mean subgenual grey matter volume of 39 and $48 \%$ in the bipolar and unipolar patients, respectively. This brain region has been implicated in the mediation of emotional and autonomic responses to socially significant or provocative stimuli.

A highly circumscribed region of the left medial prefrontal cortex was found to be impaired in patients with Asperger syndrome (a mild variant of autism) characterised by deficits in the 'theory of mind' domain (understanding other people's minds; Happé et al., 1996). Tamminga et al. (1992) demonstrated correlations of decreases in thalamus, frontal and parietal cerebral metabolism in schizophrenic patients with predominant negative symptoms. Dorsolateral prefrontal cortical dysfunction was reported by Dolan et al. (1993) to correlate with psychomotor retardation and cognitive deficits. This applied to patients with the syndromes of psychomotor poverty and 
psychomotor retardation irrespective of whether they met diagnostic criteria for a schizophrenic disorder or depressive episode. The authors argued that their findings supported the view that the study of symptoms, or symptom clusters, could provide information additional to that of traditional diagnostic systems in studying the major psychoses. Symptoms such as delusions or hallucinations could also be studied by functional neuroimaging. A recent fMRI study found the response of the temporal cortex to exogenous auditory stimulation (speech) markedly reduced while patients were experiencing hallucinations (David et al., 1996).

\section{TREATMENT EFFECTS AND BRAIN IMAGING}

Normalisation in cerebral glucose metabolic rate in the caudate nucleus has been described in patients with obsessive-compulsive disorder after successul behaviour therapy (Schwartz et al., 1996). Remission of depressive states is associated with blood flow increases in left dorsolateral prefrontal cortex and medial prefrontal cortex including the anterior cingulate (Bench et al., 1995). In a fMRI study before and during successful antidepressant treatment symptomatic improvement in two patients was accompanied by changes of blood flow activation in response to pictures with positive or negative emotional connotations. After two weeks of treatment an area of activation emerged in the right secondary visual cortex upon presentation of 'positive pictures' which had not been present while patients were depressed and anhedonic (Kalin et al., 1997). Mayberg et al. (1991), in a case report, found a $25 \%$ increase in left temporal cortical serotonin $\left(5-\mathrm{HT}_{2}\right)$ receptor binding using ${ }^{11} \mathrm{C}-\mathrm{N}$ methyl spiperone and PET after spontaneous remission of post-stroke depression. Where antipsychotic medication is concerned, associations between neuroleptic treatment and increased striatal/basal ganglia metabolic rate have been a common finding, and this applies to both typical and atypical neuroleptics (Swanson et al., 1997).

\section{SOCIAL FUNCTIONING AND NEURAL SYSTEMS}

Kopelowicz and Liberman, in their foreword to 'Cognitive Rehabilitation in Neuropsychiatry' edited by Corrigan \& Yudovsky (1996), argue that a new paradigm is emerging in rehabilitation psychia- try. The rehabilitation model directs attention to the functional capabilities and community adaptation of the mental health consumer rather than focusing on individual disease-specific symptoms. Corrigan \& Yudovsky (1996), in their book, bridge the gap from these complex measures of overall social adaptation to the issues of cognitive dysfunction and specific intervention techniques.

Premorbid low intellectual ability could be a risk factor for schizophrenia and other psychoses; David et al. (1997) found the risk for schizophrenia to vary with performance and mechanical knowledge tasks. Thus, in their large-scale epidemiological study of Swedish conscripts followed up over more than 10 years composite measures of cognitive function were associated with morbid risk. Recent research in schizophrenia underlines the importance of cognitive deficits for social functioning and community adaptation (Green, 1996). Cognition is clearly dependent upon activity within distinct neural systems. This would suggest that social functioning and brain activity are inter-related, and studying both domains jointly may open new perspectives to psychiatric research.

Modern imaging studies provide access to physiological and dysfunctional cognitive processes, and they have improved our understanding of pathogenetic mechanisms in the major psychoses. Prior to and parallel with the development of such new diagnostic tools there has, in the last fifty years, been a paradigmatic shift in psychiatric practice. The field has moved away from long-term institutional care towards therapeutic environments which tend to be small-scale, emphasise skill development and patient autonomy (Leff, 1997). They aim to target patients' needs and adapt flexibly to changing clinical and social circumstances (Knudsen \& Thornicroft, 1996). On the other hand, there has been a trend towards providing more specific treatment programmes to patients with a variety of disorders. Such efforts, in the functional psychoses, include integrated psychosocial treatment programmes, social skills training, family treatment interventions, and elaborate coping programmes for patients with persistent delusions or hallucinations (Anderson \& Adams, 1996, Brenner et al., 1996, Drury et al., 1996, Penn \& Mueser, 1996). Targeted treatment interventions require the identification of criteria which help to decide whether or not a particular intervention may help individual patients or patient groups.

As this model of service provision has evolved the importance of identifying response predictors and 
evaluating outcome has also been emphasised (Becker \& Thornicroft, 1998). The availability of targeted interventions may help in organising 'packages of care' which are time-limited, make the best use of resources and interfere relatively little with daily living routine. To mention an example in a group exposed to extreme and often long-term physical and psychological stress, Susser et al. (1997) have described a 'critical time intervention' of a few weeks in the homeless mentally ill in New York and found lasting positive effects on outcome at follow-up. Information on predictors of treatment success or failure is highly valuable where one or a range of such specific interventions are available.

From an overall perspective, the framework of psychiatric services offered to patients needs to be culturally adequate, clinically reasonable and geared towards people's social needs. On the other hand, response predictors may be relevant in deciding which specific elements should be added to a generic 'package of care'. Patients or service users might well ask for such evidence in the future, and are likely to become key stakeholders in the research process. Continuous dialogue between professionals and service users in planning the care process and an increasing scope of sophisticated single-case designs could thus converge in the future. Using modern functional neuroimaging we may be able to better understand cognitive and behavioural deficits in people suffering from schizophrenia and other functional psychoses, and we may soon be in a position to plan and implement this type of research jointly with patients in order to improve coping skills and jointly develop therapeutic programmes tailored to patients' needs.

\section{REFERENCES}

Anderson J. \& Adams C. (1996). Familiy interventions in schizophrenia. An effective but underused treatment. British Medical Journal 313, 505-506.

Andreasen N.C., Olson S.A., Dennert J.W. \& Smith M.R. (1982) Ventricular enlargement in schizophrenia: relationship to positive and negative symptoms. American Journal of Psychiatry $139,297-302$.

Andreasen N.C., Oleary D.S., Cizadlo T., Arndt S., Rezai K., Ponto L.L.B., Watkins G.L. \& Hichwa R.D. (1996). Schizophrenia and cognitive dysmetria: a positron-emission tomography study of dysfunctional prefrontal-thalamic-cerebellar circuitry. Proceedings of the National Academy of Sciences of the USA 93, 9985-9990.

Becker T. \& Thornicroft G. (1998). Community care and management of schizophrenia. Current Opinion in Psychiatry 11, 4954.
Becker T. Retz W., Hofmann E., Becker G., Teichmann E. \& Gsell W. (1995). Some methodological issues in neuroradiological research in psychiatry. Journal of Neural Transmission [General Section] 99, 7-54.

Bench C.J., Frackowiak R.S.J. \& Dolan R.J. (1995). Changes in regional cerebral blood flow on recovery from depression. Psychological Medicine 25, 247-61.

Brenner H.D., Hirsbrunner A. \& Heimberg D. (1996). integrated psychological therapy program: training in cognitive and social skills for schizophrenic patients. In Cognitive Rehabilitation for Neuropsychiatric Disorders (ed. P.W. Corrigan and S.C. Yudovsky), pp 329-348. American Psychiatric Press: Washington, DC.

Buchsbaum M.S., Someya T., Teng C.Y., Abel L., Chin S., Najafi A., Haier R.J., Wu J. \& Bunney W.E. (1996). PET and MRI of the thalamus in never medicated patietns with schizophrenia. American Journal of Psychiatry 153, 191-199.

Chua S.E. \& McKenna P.J. (1995). Schizophrenia - a brain disease? A critical review of structural and functional cerebral abnormality in the disorder. British Journal of Psychiatry $166,563-582$.

Corrigan P.W. \& Yudovsky S.C. (ed.) (1996). Cognitive Rehabilitation for Neuropsychiatric Disorders. American Psychiatric Press: Washington, DC.

David A.S., Woodruff P.W.R., Howard R., Mellers J.D.C., Brammer M., Bullmore E., Wright I., Andrew C. \& Williams S.C.R. (1996). Auditory hallucinations inhibit exogenous activation of auditory association cortex. Neuroreport 7, 932-936.

David A.S., Malmber A., Brandt L., Allebeck P. \& Lewis G (1997). IQ and risk for schizophrenia: a population-based cohort study. Psychological Medicine 27, 1311-1323.

DeLisi L.E., Sakuma M., Tew W., Kushner M., Hoff A.L. \& Grimson R. (1997). Schizophrenia as a chronic active brain process: a study of progressive brain structural change subsequent to the onset of schizophrenia. Psychiatry Research: Neuroimaging $74,129-140$.

Dolan R.J. \& Friston K.J. (1997). Functional imaging and neuropsychiatry [editorial]. Psychological Medicine 27, 1241-1246.

Dolan R.J., Bench C.J., Liddle P.F., Friston K.J., Frith C.D., Grasby P.M. \& Frackowiak R.S.J. (1993). Dorsolateral prefrontal cortex dysfunction in the major psychoses: symptom or disease specific? Journal of Neurology, Neurosurgery, and Psychiatry 56, 1290-1294.

Drevets W.C., Price J.L., Simpson Jr J.R., Todd R.D., Reich T., Vannier M. \& Raichle M.E. (1997). Subgenual prefrontal cortex abnormalities in mood disorders. Nature 386, 824-827.

Drury V., Birchwood M., Cochrane R. \& Macmillan F. (1996). Cognitive therapy and recovery from acute psychosis: a controlled trial. I. Impact on psychotic symptoms. British Journal of Psychiatry 169, 593-601.

Ebmeier K.P., Cavanagh J.T.O., Moffoot A.P.R., Glabus M.F., O'Carroll R.E. \& Goodwin G.M. (1997). Cerebral perfusion correlates of depressed mood. British Journal of Psychiatry $170,77-81$.

Figiel G.S., Krishnan K.R.R., Doraiswamy P.M. \& Nemeroff C.B. (1991). Caudate hyperintensities in elderly depressed patients with neuroleptic-induced parkinsonism. Journal of Geriatric Psychiatry and Neurology 4, 86-89.

Green M.F. (1996). What are the functional consequences of neurocognitive deficits in schizophrenia? American Journal of Psychiatry 153, 321-330.

Happé F., Ehlers S., Fletcher P., Frith U., Johansson M., Gillberg C., Dolan R., Frackowiak R. \& Frith C. (1996). 'Theory of

Epidemiologia e Psichiatria Sociale, 7, 2, 1998 
mind' in the brain. Evidence from a PET scan study of Asperger syndrome. Neuroreport 8, 197-201.

Harvey I., Ron M.A., Du Boulay G., Wicks D., Lewis S.W. \& Murray R.M. (1993). Reduction of cortical volume in schizophrenia on magnetic resonance imaging. Psychological Medicine 23, 591-604.

Hickie I., Scott E., Mitchell P., Wilhelm K., Austin M.P. \& Bennett B. (1995). Subcortical hyperintensities on magnetic resonance imaging: clinical correlates and prognostic significicance in patients with severe depression. Biological Psychiatry 37, 151-160.

Kalin N.H., Davidson R.J., Irvin W., Warner G., Orendi J.L., Sutton S.K., Mock B.J., Sorenson J.A., Lowe M. \& Turski P.A. (1997). Functional magnetic resonance imaging studies of emotional processing in normal and depressed patients: effects of venlafaxine. Journal of Clinical Psychiatry 58, Supplement No. $16,32-39$.

Keshavan M.S. \& Pettegrew J.W. (1997). Magnetic resonance spectroscopy in schizophrenia and psychotic disorders. In Brain Imaging in Clinical Psychiatry (ed. K.R.R. Krishnan and P.M. Doraiswamy), pp. 381-400. Dekker: New York.

Kindermann S.S., Karimi A., Symonds L., Brown G.G. \& Jeste D.V. (1997). Review of functional magnetic resonance imaging in schizophrenia. Schizophrenia Research 27, 143-156.

Knudsen H.C. \& Thornicroft G. (ed.) (1996). Mental Health Service Evaluation. Cambridge University Press: Cambridge.

Leff J. (ed.) (1997). Care in the Community: Illusion or Reality? Wiley: Chichester.

Martinot J.L., Pailliere Martinot M.L., Loch C., Lecrubier Y., Dao Castellana M.H., Aubin F., Allilaire J.F., Mazoyer B., Maziere B. \& Syrota A. (1994). Central D2 receptors and negative symptoms of schizophrenia. British Journal of Psychiatry 164, 27-34.

Mayberg H.S., Parikh R.M., Morris P.L.P. \& Robinson R.G. (1991). Spontaneous remission of post-stroke depression and temporal changes in cortical $\mathrm{S}_{2}$-serotonin receptors. The Journal of Neuropsychiatry and Clinical Neurosciences 3, 80-83.
Nair T.R., Christensen J.D., Kingsbury S.J., Kumar N.G., Terry W.M. \& Garver D.L. (1997). Progression of cerebroventricular enlargement and the subtyping of schizophrenia. Psychiatry Research: Neuroimaging 74, 141-150.

Okubo J., Suhara T., Susuki K., Kobayashi K., Inoue O., Terasaki O., Someya Y., Sassa T., Sudo Y., Matsushima E., Iyo M., Tateno Y. \& Toru M. (1997). Decreased prefrontal dopamine D1 receptors in schizophrenia revealed by PET. Nature 385, 634636.

Penn D.L. \& Mueser K.T. (1996). Research update on the psychosocial treatment of schizophrenia. American Journal of Psychiatry 153, 607-617.

Schwartz J.M., Stoessel P.W., Baxter L.R., Martin K.M. \& Phelps M.E. (1996). Systematic changes in cerebral glucose metabolic rate after successful behaviour modification treatment of obsessive-compulsive disorder. Archives of General Psychiatry 53, 109-113.

Susser E., Valencia E., Conover S., Felix A., Tsai W.Y. \& Wyatt R.J. (1997). Preventing recurrent homelessness among mentally ill men: a 'critical time' intervention after discharge from a shelter. American Journal of Public Health 87, 256-262.

Swanson C.L., Harper Mozley L.M. \& Gur R.E. (1997). Positron emission tomography studies of cerebral metabolism and blood flow in schizophrenia. In Brain Imaging in Clinical Psy. chiatry (ed. K.R.R. Krishnan and P.M. Doraiswamy), pp. 401424. Dekker: New York.

Tamminga C.A., Thaker G.K., Buchanan R., Kirkpatrick B., Alphs L.D., Chase T.N. \& Carpenter W.T. (1992). Limbic system abnormalities identified in schizophrenia using positron emission tomography with fluorodeoxyglucose and neocortical alterations with deficit syndrome. Archives of General Psychiatry 49, 522-530.

Van Os J., Fahy T.A., Jones P., Harvey I., Lewis S., Williams M., Toone B. \& Murray R. (1995). Increased intracerebral cerebrospinal fluid spaces predict unemployment and negative symptoms in psychotic illness: a prospective study. British Journal of Psychiatry 166, 750-758. 